\title{
Visualização das transformações da paisagem belo-horizontina: De Aarão Reis aos dias atuais
}

\author{
Landscape transformation views of Belo Horizonte City: From Aarão Reis until \\ nowadays
}

\author{
Thiago Alfenas Fialho, Roberto Eustaáquio dos Santos
}

História Urbana, Cartografia Histórica, GIS-Histórico, Belo Horizonte

\begin{abstract}
Este artigo descreve dois procedimentos metodológicos associados à visualização das transformações físicas ocorridas na paisagem de Belo Horizonte em pouco mais de um século de urbanização. No primeiro deles, realizamos um estudo comparativo entre as paisagens natural e atual, baseados numa simulação em ambiente computacional que recompõe a topografia de uma parcela da cidade, compreendida pelos limites da Avenida do Contorno, cujo perímetro foi lançado sobre a Planta Geodésica, Topográfica e Cadastral da Nova Capital. Essa e uma série de outras plantas produzidas entre 1894 e 1898 resultam de informações das Cadernetas de Campo produzidas pela Divisão de Estudos e Preparo do Solo da Comissão Construtora da Nova Capital, em que estão registrados os dados utilizados para estudos dos recursos naturais, cadastro das propriedades públicas e privadas e a representação gráfica da topografia que serviu de base para o plano urbano traçado pelo engenheiro Aarão Reis. A fac-similização das imagens dessas cadernetas, visando ampliar sua disponibilidade para consulta, constitui o segundo procedimento aqui descrito. Essas duas investigações são pontos de partida para uma História das Obras Públicas em Belo Horizonte.
\end{abstract}

\section{Urban History, Historical Cartography, Historical-GIS, Belo Horizonte}

This paper describes two methodological procedures related to the visualization of landscape changes in Belo Horizonte in a little more than a century of urbanization. The first of them deals with a comparative study between natural and current's landscape. This simulation recomposed a plot limited to the Avenidado-Contorno's projection upon the Planta Geodésica, Topográfica e Cadastral da Nova Capital. Like many others plans produced between 1894 e 1898, this plan resulted from a topographic survey made by the Divisão de Estudos e Preparo do Solo da Comissão Construtora de Belo Horizonte (Division of Studies and Earthworks), whose technical logs registered the natural resources, land ownership and topography data. The second procedure described here deals with an image treatment of these logs, aiming their publishing in electronic media. Both procedures are starting points to a History of Public Works in Belo Horizonte.

\section{Introdução}

A descrição dos procedimentos metodológicos aqui apresentados constituem um passo a mais no desenvolvimento de uma pesquisa acerca da História Urbana da cidade Belo Horizonte, com foco nas obras públicas ${ }^{1}$. Trata-se, por um lado, de um estudo comparativo entre dois

\footnotetext{
${ }^{1}$ A pesquisa vem sendo desenvolvida a partir de dois projetos, a saber: BASES QUANTITATIVAS PARA UMA HISTÓRIA DAS OBRAS PÚBLICAS EM BELO HORIZONTE (Edital PRPq-UFMG 01/2013) e UM SÉCULO DE OBRAS
}

T. A. Fialho, R. E. dos Santos. 2015. Visualização das transformações da paisagem belo-horizontina: De Aarão Reis aos dias atuais. In: C. G. Spinillo; L. M. Fadel; V. T. Souto; T. B. P. Silva \& R. J. Camara (Eds). Anais [Pôster] do 7º Congresso Internacional de Design da Informação/ Proceedings [Poster] of the 7th Information Design International Conference | CIDI 2015 [Blucher Design Proceedings, num.2, vol.2]. São Paulo: Blucher, 2015. ISSN 2318-6968, DOI 10.5151/designpro-CIDI2015-cidi_164 
extremos: o "sítio natural" da cidade, que serviu de base para a implantação do projeto urbanístico de Aarão Reis e a ocupação urbana atual; por outro lado, trata-se da facsimilização do registro fotográfico das Cadernetas de Campo da Divisão de Estudos e Preparo do Solo da Comissão Construtora da Nova Capital (CCNC). Se o primeiro procedimento, em vista do volume de movimentação de terra indicado na simulação em ambiente computacional aguça nossa curiosidade sobre as razões, períodos e os meios utilizados nessa operação, o segundo pretende preservar a integridade e ampliar o acesso às informações das Cadernetas de Campo da Comissão Construtora ${ }^{2}$. Dessa forma, enfatizamos o propósito de nosso trabalho, neste momento, de sistematizar fontes primárias e de formular questões fundamentais para futuras ações de pesquisa, utilizando recursos eletrônicos disponíveis, tais como os Geographical Information System, os Computer Aided Design e os softwares gráficos.

Os primeiros testes para visualização da movimentação de terra ocorrida entre o levantamento realizado pela Divisão de Estudos e Preparo do Solo da CCNC e os dias atuais, restringiram-se à parcela delimitada pelo traçado da atual Avenida do Contorno, cuja projeção foi lançada sobre a Planta Geodésica, Topográfica e Cadastral da Nova Capitaß ${ }^{\beta}$ (Figura 01).

Apresentamos, a seguir, a metodologia empregada nesse procedimento.

Figura 01: Planta Geodésica, Topográfica e Cadastral da Nova Capital. Adaptada pelos autores sobre planta original, guardada pelo Arquivo Público Mineiro.

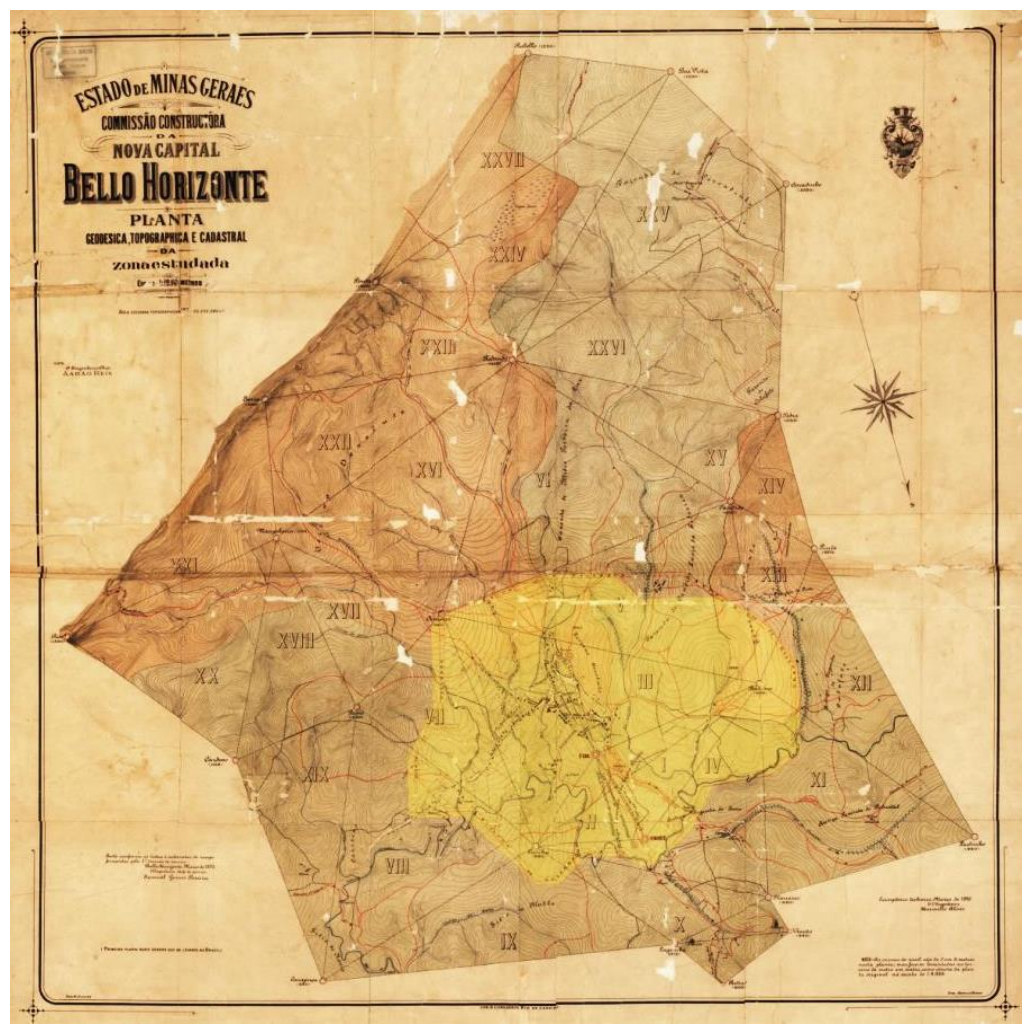

\section{Metolodologia da reconstituição do sítio natural de Belo Horizonte}

Projetada pela CCNC sob a coordenação do engenheiro Aarão Reis, entre 1894 e 1897, Belo Horizonte foi das primeiras cidades planejadas dentro de critérios cientítificos higienistas e dos ideais republicanos no Brasil, como aponta o "Engenheiro Aarão Reis: O Progresso como Missão":

PÚBLICAS: CRONOLOGIA GEORREFERENCIADA DOS RELATÓRIOS DOS PREFEITOS DE BELO HORIZONTE 1889-2005 (Edital Chamada Universal - MCTI/CNPq n.14/2013).

${ }^{2}$ As Cadernetas de Campo da Comissão Construtora da Nova Capital pertencem ao acervo do Museu Abílio Barreto.

${ }^{3}$ A Planta Geodésica, Topográfica e Cadastral da Nova Capital pertence ao acervo do Arquivo Público Mineiro. 
Belo Horizonte foi criada num momento de transição, em que se operavam mudanças do discurso urbanístico internacional: o retorno aos traçados serpenteados e a adoção de traçados policêntricos levando em conta as curvas de nível preconizadas por Camillo Sitte, são-lhe de pouco posterior. [...] Nessa planta faz-se alusão, ao mesmo tempo, aos princípios utopistas e higienistas (que muitas vezes são os mesmos), ao se hierarquizar o espaço em termos da distribuição de equipamentos, da localização funcional dos serviços em nome da tríade salubridade, comodidade, embelezamento.

(SALGUEIRO, 1997, p.155)

Elementos chave do traçado urbano da cidade incluem uma malha perpendicular de ruas cortadas por avenidas em diagonal, quarteirões de dimensões regulares e uma avenida em torno de seu perímetro: a Avenida do Contorno. O limite definido pela avenida configura a área investigada, uma vez que os investimentos nas obras de urbanização nos primeiros anos após a inauguração foram feitos predominantemente dentro desses limites. Esse espaço foi considerado entre dois extremos temporais: 1894 (dados extraídos da Planta Geodésica, Topográfica e Cadastral da Nova Capital, um dos subprodutos das Cadernetas de Campo) e 2010 (dados extraídos da Base Cadastral PRODABEL-2010, disponibilizada pela Prefeitura Municipal de Belo Horizonte).

Em primeiro lugar, tratamos de ajustar a orientação das fontes e de identificar o atual perímetro da Avenida do Contorno na base PRODABEL-2010. Feito isso, sobrepusemos esse perímetro sobre a imagem de satélite do Google Earth (2015) e também sobre a Planta Geodésica, Topográfica e Cadastral da Nova Capital. Tais recortes cartográficos estão ilustrados nas Figuras 02 e 03. A partir disso, pudemos elaborar um esquema comparativo que aparece no Quadro 01, entre os sítios original e atual.

Num segundo momento, isolamos as curvas de nível nas representações dos dois períodos. Para identificar as curvas do terreno urbanizado, recortamos os limites da Avenida do Contorno sobre a base cadastral da PBH. Para recuperar as curvas de nível do sítio natural, tivemos de redesenhar todas as linhas desse recorte da Planta Geodésica no AutoCAD, num processo de vetorização. Em seguida, atribuimos à cada linha a informação da elevação correspondente, uma a uma. O resultado desse processo pode ser conferido nas Figuras 04 e 05.

Além disso, redesenhamos o arruamento e os cursos d'água originais, baseados na Planta Geral da Cidade de Minas (Figura 06). Na Figura 07, está representado o traçado urbano atual. 
Quadro 01: Estudo comparativo entre os sítios natural e atual.

Figura 02: Fragmento da Planta Geodésica, Topográfica e Cadastral da Nova Capital, em que estão registrados os aspectos físicos correspondentes aos limites da atual Avenida do Contorno.

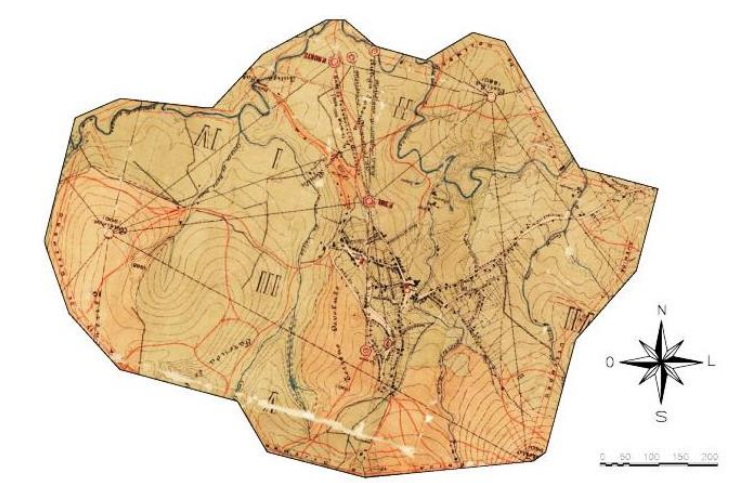

Figura 04: Curvas de nível transpostas para ambiente computacional a partir do fragmento da Planta Geodésica, Topográfica e Cadastral da Nova Capital.

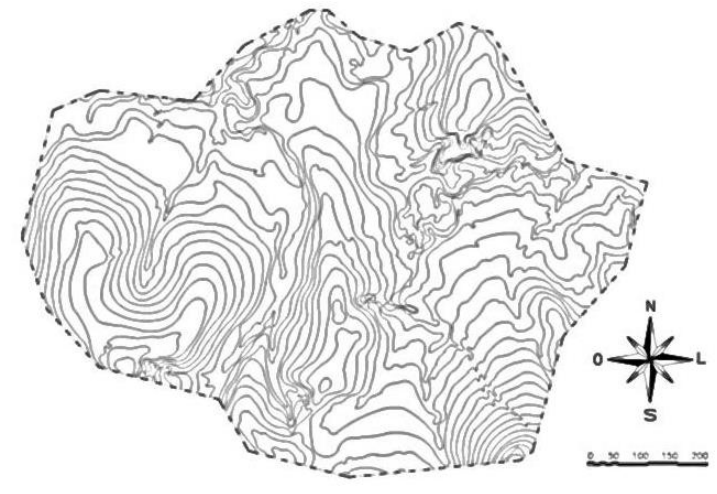

Figura 06: Arruamento e rede de drenagem extraídos do fragmento da Planta Geral da Cidade de Minas.

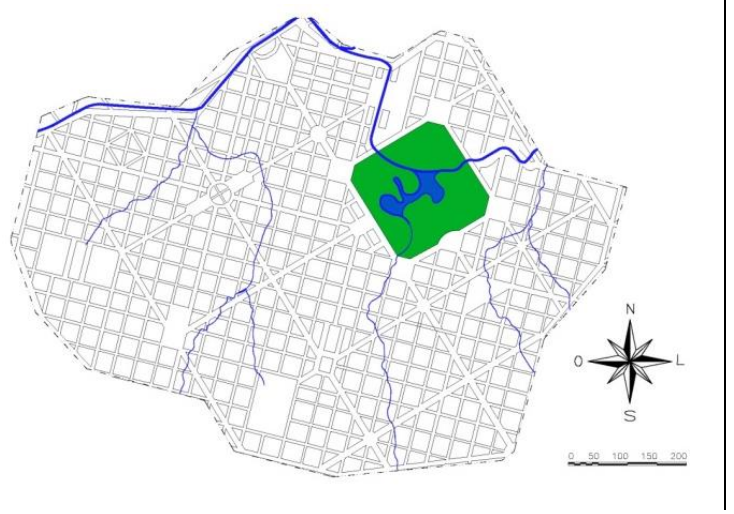

Figura 03: Vista aérea extraída do Google Earth, em que se pode visualizar a parcela compreendida pela Avenida do Contorno, em 2015.

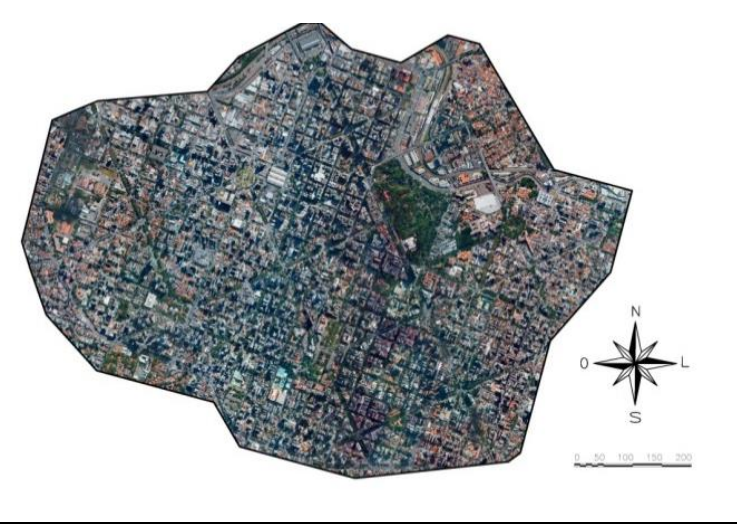

Figura 05: Curvas de nível do sítio atual do fragmento compreendido pela Avenida do Contorno, em 2010.

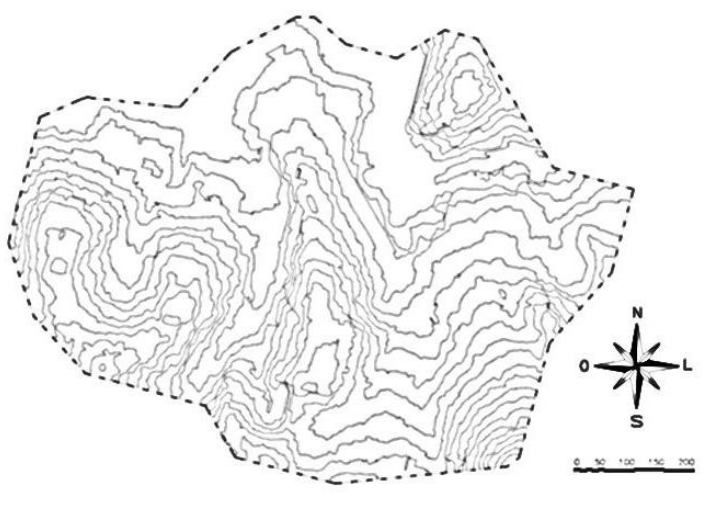

Figura 07: Arruamento e rede de drenagem extraídos da Base Cadastral PRODABEL-2010.

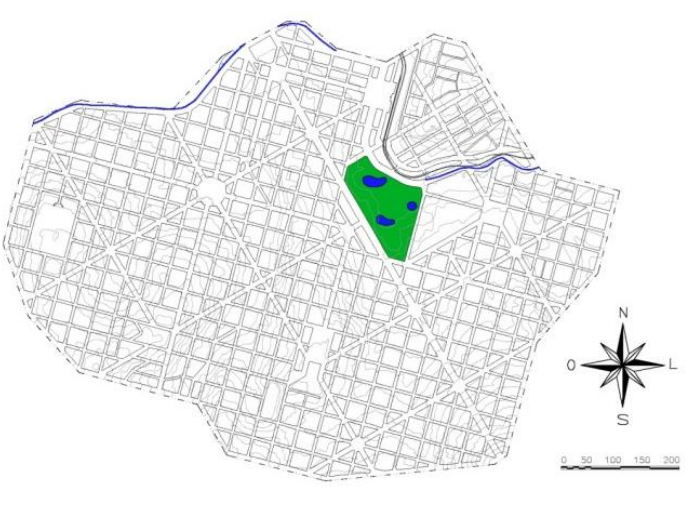

Entre outras coisas, a comparação entre as plantas (Figuras 06 e 07) nos indica diferenças na malha inicialmente planejada e a atual, tal como a significativa redução da área do Parque Municipal e o tamponamento dos córregos, especialmente do Ribeirão Arrudas. A canalização desse curso d'água foi prioritária nos primeiros anos após a inauguração da cidade. Tal necessidade parece estar associada ao prosseguimento da construção dos coletores de esgoto que margeiam o seu leito (Figura 08). 
Figura 08: Retificação e canalização do Ribeirão Arrudas: trecho da obra que permitiu o prolongamento da Avenida do Canal (hoje Avenida dos Andradas) na área destinada ao Parque Municipal, 1926. Pertence ao Arquivo Público Mineiro.

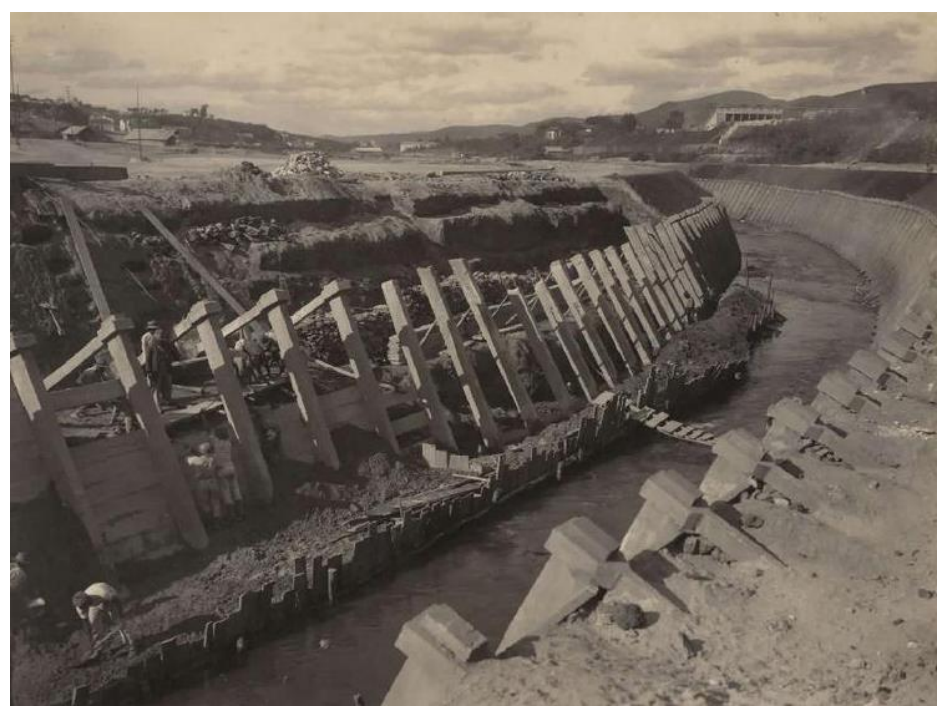

A supressão da Praça das Escolas, a abertura da Avenida Amazonas e da atual Praça Raul Soares também são evidências nas alterações da malha urbana prevista na Planta Geral da Cidade de Minas. Na verdade, esse traçado nunca chegou a ser completamente executado, conforme atesta o seguinte trecho do Relatório Anual da Prefeitura de Belo Horizonte - 19221923:

A planta da cidade, estudada pela Comissão Construtora, era projeto a ser realizado; sucede, porém, que este foi executado apenas em parte, e que os elementos necessários à execução da outra e de quase todos os detalhes não foram respeitados, ou não existiram ou perderam-se. ( $\mathrm{PBH}$, Relatório de 1922-1923, p.24. Grafia original).

Outra questão relevante diz respeito ao tratamamento dispensado aos cursos d'água. Como pode ser visto no Quadro 02, em que comparamos os cursos levantados pela Comissão Construtora em 1894 e os representados na Planta Geral da Cidade de Minas, em grande medida, o traçado urbanístico parece desconsiderar o sítio natural, chegando a suprimir trechos dos córregos levantados.

Quadro 02: Comparação entre os sítios natural e o projetado pela Comissão Constutora, com destaque para os cursos d'água à céu aberto.

Figura 09: Fragmento da Planta Geodésica, Topográfica e Cadastral da Nova Capital, com destaque para os cursos d'água levantados pela Comissão Construtora, entre 1894 e 1898.

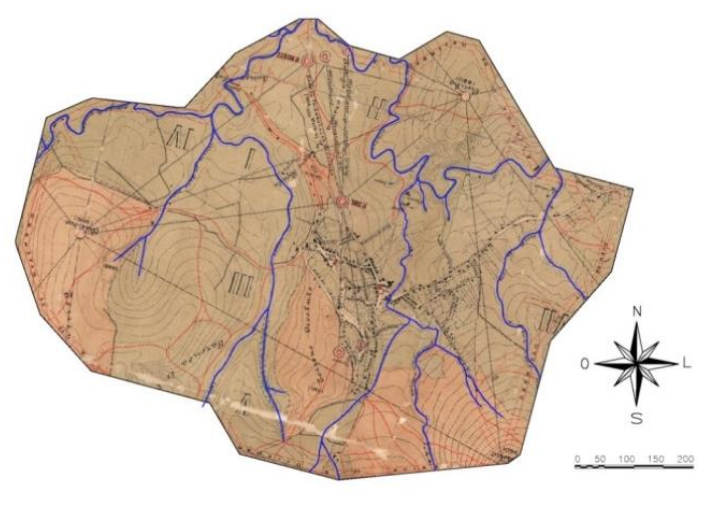

Figura 10: Fragmento da Planta Geral da Cidade de Minas, elaborada pelo engenheiro Aarão Reis, em que destacamos a preservação da maior parte da rede de drenagem natural.

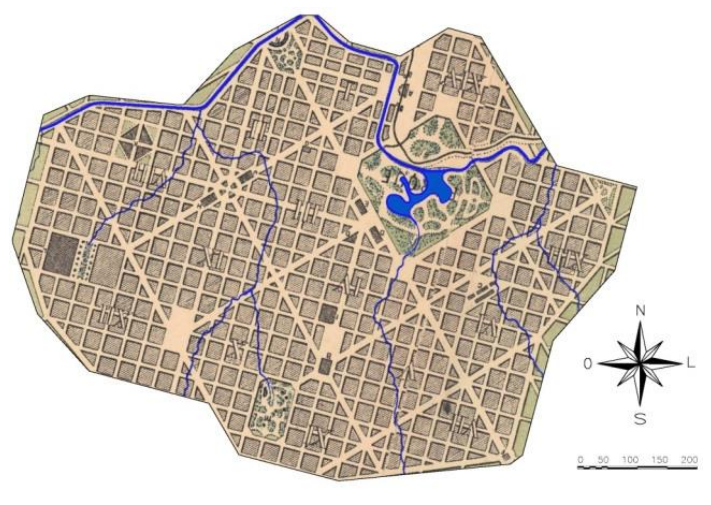

A Figura 11 esboça uma síntese das transformações resultantes de pouco mais de um século de ocupação urbana. Nossa intenção é desenvolver um tipo de linguagem gráfica que 
facilite a leitura de dados dessa natureza, considerando sua evolução histórica, de modo a que o cidadão comum possa entender os processos urbanos, ampliando assim sua capacidade de participar das decisões acerca dos rumos da cidade.

gura 11: Visualização da ocupação urbana, com ênfase para o tamponamento dos cursos d'água. Elaborada através dos softwares SketchUp e Adobe Photoshop, a partir dos aspectos apresentados no Quadro 01.

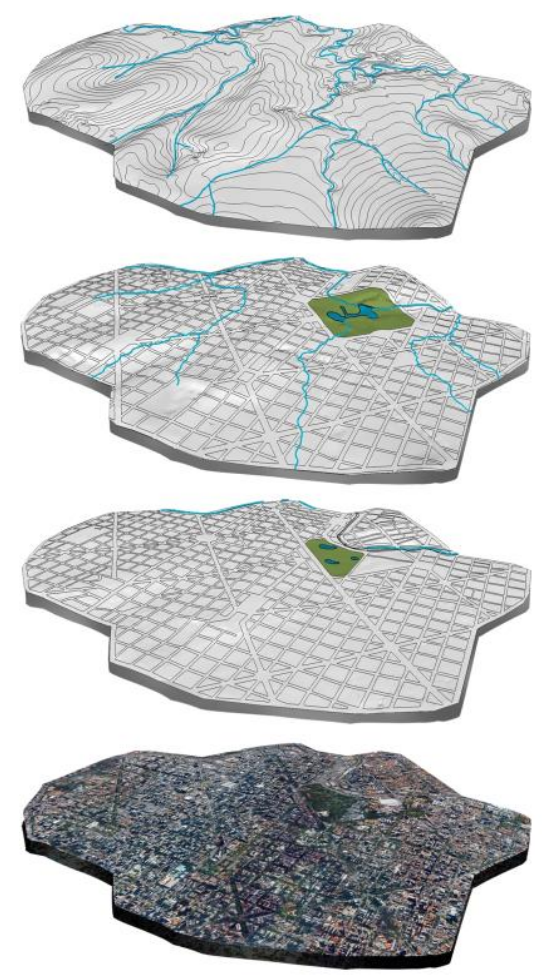

\section{Alguns resultados preliminares}

A partir da transposição das curvas de nível do sítio natural da área de estudo (Figura 04), pudemos compará-las ao terreno atual, cujas curvas estão apresentadas na Figura 05. Desse modo, elaboramos um modelo digital de elevação, através do AutoCAD Civil 3D. Para isso, arbitramos a elevação corresponde a 900 metros como referência, devido ao fato de que nessa cota o terreno natural foi minimamente alterado. A partir disso, foram utilizados procedimentos padrão do software e que, por isso, não cabe serem descritos aqui. Tal modelo teve como resultado a Figura 12: um mapa em que são apresentadas as diferenças de níveis entre as plantas de 1894 e a de 2010. Quanto mais avermelhada a cor, mais aterros foram executados; quanto mais esverdeada, mais cortes realizados.

Figura 12: Modelo Digital de Elevação de comparação dos anos de 1895 e 2010. Elaborado a partir das bases computadorizada (1894) e PRODABEL-2010.

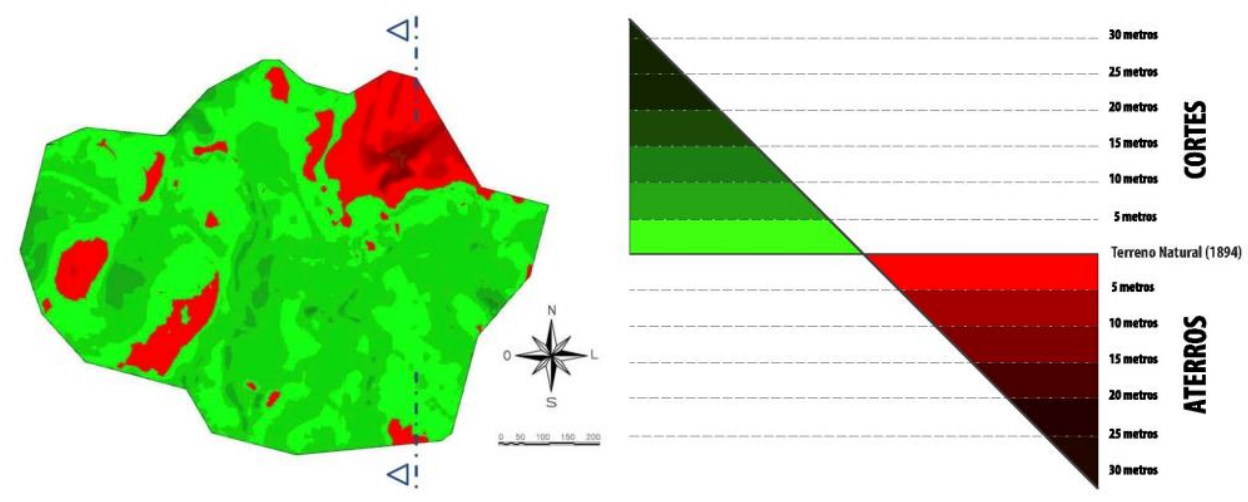


Além do modelo digital de elevação, o software nos forneceu informações interessantes sobre a área estudada. Trata-se do volume de movimentação de terra realizado nesse século de urbanização, conforme a Tabela 1.

Tabela 1: Síntese dos resultados volumétricos.

\begin{tabular}{l|l|l} 
Área de Superfície $\left(\mathbf{m}^{2}\right)$ & Volume de Corte $\left(\mathbf{m}^{3}\right)$ & Volume de Aterro $\left(\mathbf{m}^{3}\right)$ \\
\hline $8.993 .245,88$ & $9.380 .389,82$ & $42.107 .913,19$ \\
\hline Volume Total $\left(\mathbf{m}^{3}\right)$ & $51.488 .303,01$ & \\
\hline
\end{tabular}

Embora tais dados não estejam isentos de imprecisões, chama atenção o volume de aterros ser maior do que o volume de cortes. A coerência desse dado necessita ser verificada. Outro aspecto, fácil de perceber, é que o plano urbano de Belo Horizonte desconsidera os córregos, impondo-lhes um novo traçado. As subsequentes administrações públicas não fugiram a essa lógica e incentivaram as canalizações e tamponamentos, em que são comuns os aterros de leitos naturais e os desvios dos cursos d'água de modo a adaptá-los à malha urbana.

Como podemos verificar no Quadro 03, os movimentos de terra estão mais concentrados na porção nordeste da área estudada, mais especificamente nas regiões hoje correspondentes à Praça da Estação, ao entorno da Avenida Assis Chateaubriand e, especialmente, ao trecho do Ribeirão Arrudas lindeiro ao Parque Municipal.

Quadro 03: Sobreposição do modelo digital de elevação aos traçados urbanos em 1894 e em 2010.

Figura 13: Sobreposição do modelo digital de elevação ao traçado projetado.

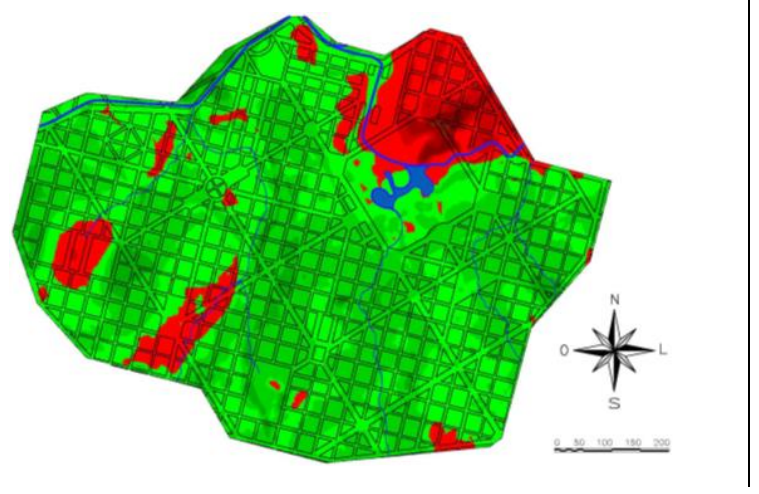

Figura 14: Sobreposição do modelo digital de elevação ao traçado urbano atual.

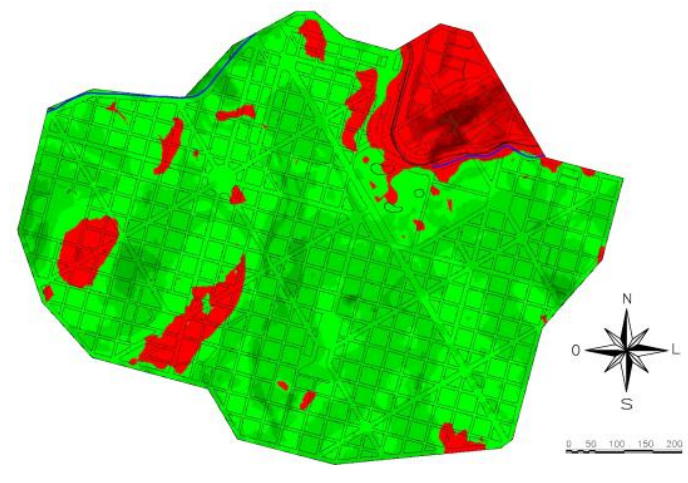

Em números atuais, para transportar o volume total de terra - somados os volumes de corte e aterro - seriam necessárias cerca de 6.500 .000 caçambas com capacidade para $8 \mathrm{~m}^{3}$ por viagem. Na época de implantação da capital, todavia, o transporte da terra era realizado predominantemente por meio de carroças cujos volumes se aproximam de $1,2 \mathrm{~m}^{3}$. Nesse caso, seriam precisas aproximadamente 43.000 .000 carroças.

Ressaltamos ainda que as movimentações de terra nessa porção da cidade foram concentradas nos primeiros anos da ocupação, conforme dados extraídos dos Relatórios Anuais da Prefeitura de Belo Horizonte 4 e apresentados na Tabela 2 e no gráfico da figura 15.

\footnotetext{
${ }^{4}$ Os relatórios foram recentemente disponibilizados on-line pelo Arquivo Público da Cidade de Belo Horizonte, graças a um convênio entre a PBH, a Harvard University e The Andrew W. Mellon Foundation.
} 
Tabela 2: Distribuição dos volumes de movimentação de terra entre 1889 e 1930 . Elaborada com base nos Relatórios Anuais da Prefeitura de Belo Horizonte - 1899-1930

\begin{tabular}{l|l} 
Intervalos de Tempo (em anos) & Quantidade de volumes $\left(\mathbf{m}^{3}\right)$ \\
\hline $1889-1905$ & 3.774 .956 \\
\hline $1906-1910$ & 720.850 \\
\hline $1911-1915$ & 4.614 .130 \\
\hline $1916-1920$ & 14.419 .845 \\
\hline $1921-1925$ & 485.643 \\
\hline $1926-1930$ & 6.466 .003 \\
\hline TOTAL & $\mathbf{3 0 . 4 8 1 . 4 2 7}$ \\
\hline
\end{tabular}

Figura 15: Gráfico de distribuição dos volumes de terra $\left(\mathrm{em} \mathrm{m}^{3}\right)$ entre 1889 e 1930. Elaborado com base nos Relatórios Anuais da Prefeitura de Belo Horizonte.

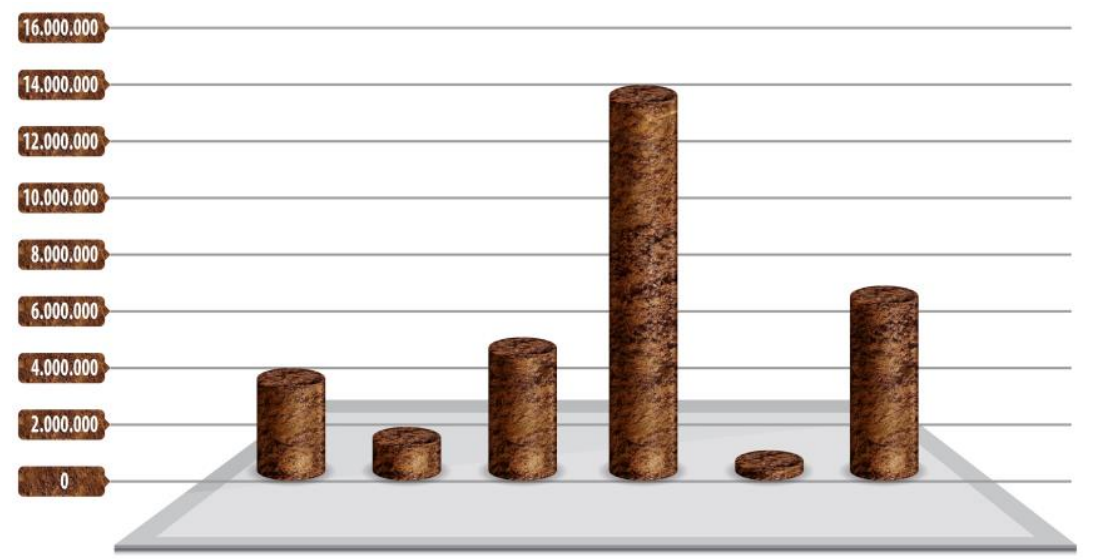

1889-1905 1906-1910 1911-1915 1916-1920 1921-1925 1926-1930

Ainda que constituam fonte preciosa de informações, é preciso mencionar que os dados dos Relatórios Anuais da Prefeitura de Belo Horizonte apresentam descontinuidades. No entanto, parece claro que o trabalho de movimentação de terra foi concentrado nesse período para fins de retificação dos cursos d'água.

\section{A fac-similização das Cadernetas de Campo e seus desdobramentos}

Paralelamente, o trabalho de reconstituição do sítio natural da cidade vem sendo complementado pela fac-similização das Cadernetas de Campo. Atualmente, o Museu Histórico Abílio Barreto guarda em seu acervo as cadernetas produzidas pela Divisão de Estudos e Preparo do Solo da Comissão Construtora de Belo Horizonte. Trata-se de 671 documentos, produzidos entre 1894 e 1898, em que estão registrados os aspectos físicos do sítio natural da cidade que viriam a ser base do projeto de assentamento do plano urbano traçado pelo engenheiro Aarão Reis. O agrupamento das informações contidas nesses documentos resultou numa série de plantas - entre elas, as que servem de base para este estudo.

A primeira etapa do processo de fac-similização foi realizada entre os meses de outubro e dezembro de 2014. A fase inicial consistiu na realização de cerca de 27.000 fotografias, em que foram registradas todas as páginas das Cadernetas. Neste ano, demos início ao processo de edição dessas fotografias, que consiste no aperfeiçoamento das imagens e inserção da marca de procedência. Quando todas as fotografias correspondentes a uma única caderneta são concluídas, é gerado um arquivo único do tipo PDF (Figura 16).

Futuramente, quando esse trabalho estiver finalizado, o material será disponibilizado virtualmente, tornando-se referencial para futuros estudos acerca da evolução urbana da cidade. Também pretendemos transpor todos os dados topográficos contidos nesses documentos para os Sistemas de Informação Geográfica. Com isso, esperamos reconstituir o sítio natural com a maior precisão que as tecnologias atuais permitem. 
Figura 16: Edição das fotografias e transformação em arquivos do tipo PDF.

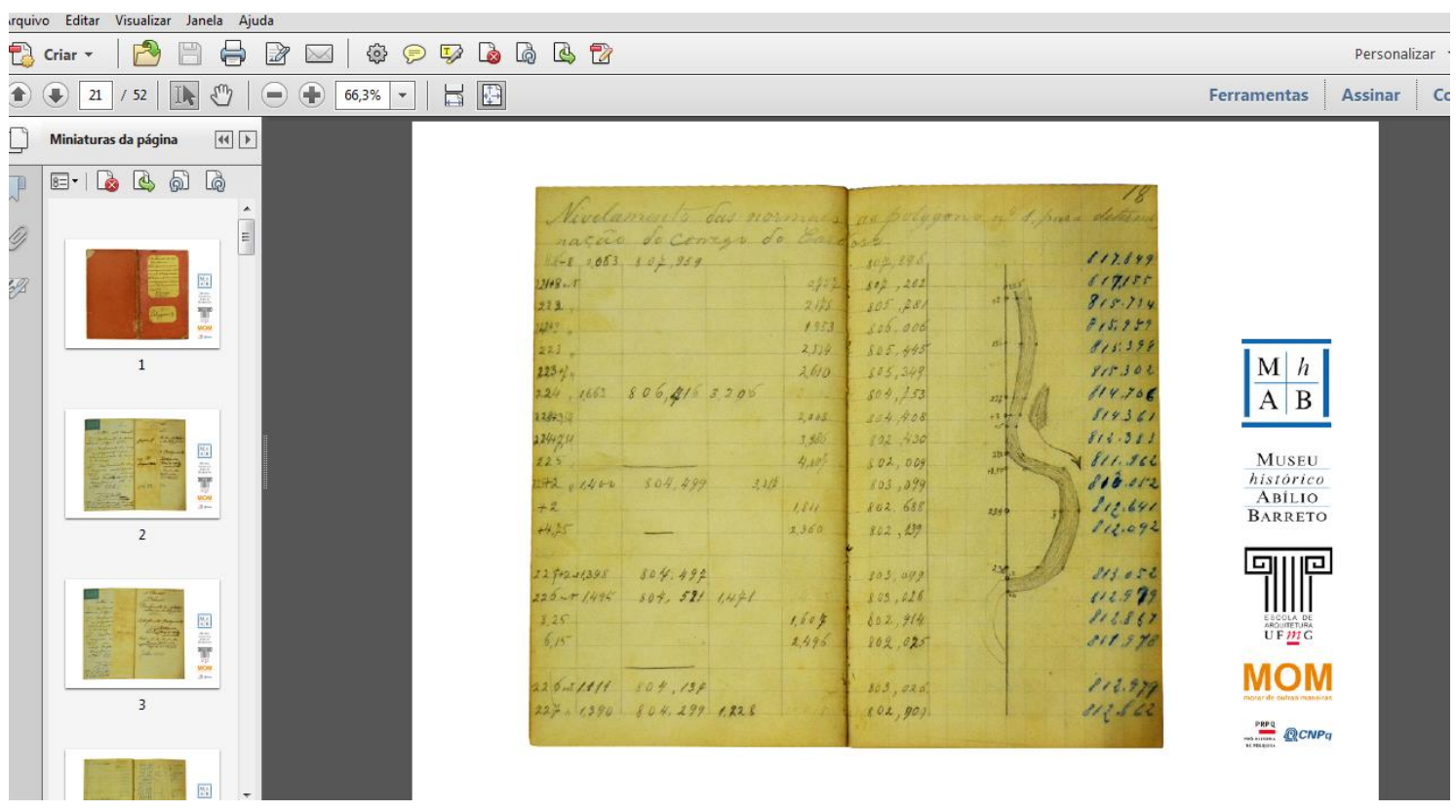

\section{Conclusão}

A título de conclusão, gostaríamos de reafirmar nossa intenção de prosseguir realizando experimentos a partir do uso de ferramentas eletrônicas para reconstituir a História Urbana de Belo Horizonte por meio do contraste entre a simulação de seu "sítio natural" e os diversos estágios de sua evolução ao longo do tempo, a exemplo do que apresenta este artigo. Com isso, buscamos tanto ampliar a capacidade de compreensão dos fenômenos urbanos ao longo do tempo, quanto democratizar o acesso a esses dados pela população em geral. Acreditamos que a visualização dos dados espaciais, especialmente a visualização de dados espaciais ao longo do tempo - o chamado SIG histórico - pode ter grande potencial transformador da sociedade.

\section{Agradecimento}

Este texto não teria sido possível sem o apoio da PRPq-UFMG e do CNPq. Agradecemos ao acadêmico Vinícius Fortes de Morais Carvalho pelo apoio no uso do AutoCAD Civil 3D e ao Museu Histórico Abílio Barreto pela disponibilização das Cadernetas de Campo.

\section{Referências}

ESTADO DE MINAS GERAIS (MG). Planta Geodésica, Topográfica e Cadastral da Nova Capital. Elaborada pela Comissão Construtora da Nova Capital. Rio de Janeiro, Companhia de Artes Gráficas, escala 1:10.000, dimensão: 105×106cm.

ESTADO DE MINAS GERAIS (MG). 1895. Planta Geral da Cidade de Minas. Rio de Janeiro, Companhia de Artes Gráficas, escala 1:10.000, dimensão: 98×100cm.

PREFEITURA DE BELO HORIZONTE (PBH). 2010. Base Cadastral PRODABEL-2010. Belo Horizonte, PBH. Disponível em www.pbh.gov.br (acesso em Abril de 2015).

PREFEITURA DE BELO HORIZONTE (PBH). 1919. Relatório apresentado ao Conselho Deliberativo pelo Prefeito Affonso Vaz de Mello. Belo Horizonte, Imprensa Oficial do Estado de Minas Gerais.

PREFEITURA DE BELO HORIZONTE (PBH). 1902. Relatório apresentado ao Conselho Deliberativo pelo Prefeito Benjamin Pinto Monteiro. Belo Horizonte, Imprensa Oficial do Estado de Minas Gerais. 
PREFEITURA DE BELO HORIZONTE (PBH). 1923. Relatório apresentado ao Conselho Deliberativo pelo Prefeito Flavio Fernandes dos Santos. Belo Horizonte, Imprensa Oficial do Estado de Minas Gerais.

SALGUEIRO, H. A. 1997. Engenheiro Aarão Reis: O progresso como missão. Fundação João Pinheiro, Centro de Estudos Históricos e Culturais, Belo Horizonte.

\section{Sobre os autores}

Thiago Alfenas Fialho, técnico (2009) em Edificações pelo CEFET-MG; graduando (2015) em Arquitetura e Urbanismo pela UFMG, Brasil, alfenasthiago@gmail.com.

Roberto Eustaáquio dos Santos, graduado (1983) e mestre (2002) em Arquitetura pela UFMG; doutor (2008) em Educação também pela UFMG, Brasil, ro1234ro@gmail.com. 